\title{
Health-related quality-of-life and treatment satisfaction of individuals with hemophilia $A$ treated with turoctocog alfa pegol (N8-GP): a new recombinant extended half-life FVIII
}

This article was published in the following Dove Medical Press journal:

Patient Preference and Adherence

\section{Susan Kearney, ${ }^{1, *}$ Leslie J Raffini, ${ }^{2}$ Tan P Pham, ${ }^{3}$ Xin Ying Lee, ${ }^{4}$ Sylvia von Mackensen, ${ }^{5, *}$ Andrea Landorph, ${ }^{6}$ Hideyuki Takedani, ${ }^{7}$ Johannes Oldenburg ${ }^{8}$ \\ 'Center for Bleeding and Clotting Disorders, Children's Hospital Minnesota, Minneapolis, MN, USA; ${ }^{2}$ Division of Hematology, The Children's Hospital of Philadelphia, Perelman School of Medicine at the University of Pennsylvania, Philadelphia, PA, USA; ${ }^{3}$ Mapi (an Icon plc company), Boston, MA, USA; ${ }^{4}$ Global Biopharm Patient Access, Biopharm Operations, Novo Nordisk A/S, Copenhagen, Denmark; ${ }^{5}$ Department of Medical Psychology, University Medical Centre Hamburg-Eppendorf, Hamburg, Germany; ${ }^{6}$ Medical \& Science, Biopharm Operations, Novo Nordisk A/S, Copenhagen, Denmark; ${ }^{7}$ Department of Joint Surgery, Research Hospital of the Institute of Medical Science, The University of Tokyo, Tokyo, Japan; ${ }^{8}$ Institute of Experimental Haematology and Transfusion Medicine, University Clinic Bonn, Bonn, Germany \\ *These authors contributed equally to this work}

Correspondence: Sylvia von Mackensen Department of Medical Psychology, University Medical Centre HamburgEppendorf, Martinistr. 52, Hamburg 20246, Germany

Tel +49 I72 6822759

Fax +494074 1058170

Email s.mackensen@uke.de
Background: Prophylactic treatment regimens lead to improvements in health-related qualityof-life (HRQoL) among individuals with hemophilia. Turoctocog alfa pegol (N8-GP) provides the benefit of extending the duration of protection from bleeding and reducing the number of injections, which is expected to impact HRQoL and treatment satisfaction (TS).

Aim: To investigate the HRQoL and TS of patients with severe hemophilia A from two phase III trials evaluating the safety and efficacy of N8-GP.

Methods: HRQoL was assessed using the Haemo-QoL (reported by children and their parents) and Haem-A-QoL (reported by adults). TS was assessed using Hemo-Sat. Domain and total scores for all questionnaires ranged from 0 to 100, with lower scores indicating a better HRQoL or TS. A negative change in score indicates an improvement in HRQoL/TS.

Results: Mean changes in HRQoL scores were reported for 14 children aged 4-7 years, 21 children aged $8-11$ years, 10 adolescents aged $13-16$ years, and 163 adults (17 years and above). Mean changes in children/adolescents-reported Haemo-QoL total score were -14.0 for ages $4-7$ years, -3.6 for ages $8-11$ years, and -0.1 for ages $13-16$ years. Mean changes in parentreported Haemo-QoL total scores were -11.5 for $4-7$ years, -8.6 for ages $8-11$ years, and -4.0 for 13-16 years. Adults' mean change in Haem-A-QoL total score was -3.1 for those receiving on-demand treatment and -2.3 for those receiving prophylaxis treatment. High levels of TS with N8-GP were reported by parents of children/adolescents and the adults at the end of the trial. Conclusion: While most patients reported a relatively good baseline HRQoL when entering the respective trials, the HRQoL of patients was either maintained or further improved when treated with N8-GP. Adults and parents of children and adolescents reported a high level of treatment satisfaction with N8-GP.

Keywords: hemophilia A, turoctocog alfa pegol, health-related quality-of-life, children, adults, treatment satisfaction

\section{Introduction}

Hemophilia A is characterized by a deficiency or protein abnormality in factor VIII resulting in recurrent bleeding episodes, most commonly in joints. Hemarthrosis may lead to pain, muscular atrophy, arthropathy and joint deformities. ${ }^{1}$ Individuals with joint damage may have limited mobility; while those without joint damage may limit their activities to minimize their risk of bleeding. ${ }^{2}$ In addition to the physical impairments, hemophilia can impact a patient's psychological, social, and economic well-being. ${ }^{2-4}$ 
Standard of care of patients with severe hemophilia is intravenous replacement of FVIII either through episodic ("on demand") treatment given at the time of bleeding or other hemostatic challenges or prophylactic treatment which involves several injections per week to prevent bleeding. The half-life of standard recombinant FVIII (rFVIII) products is 10-12 hours. ${ }^{1,5}$ More recently, extended half-life (EHL) factor concentrates have been developed which can potentially benefit patients by extending the duration of protection from bleeding, reducing the number of injections and/or increasing the patient's trough factor level which could reduce bleeding. ${ }^{5,6}$ Prophylactic treatment regimens have led to improvements in health-related quality-of-life (HRQoL) among individuals with hemophilia. ${ }^{7-10}$

Turoctocog alfa pegol (N8-GP, Novo Nordisk, Bagsværd, Denmark), an EHL glycoPEGylated rFVIII product, was developed for the prevention and treatment of bleeds in hemophilia A patients. N8-GP was previously demonstrated to result in a 1.6-fold prolongation of mean terminal half-life. ${ }^{11}$ Given the potential advantages of EHL factor concentrates, it is hypothesized that N8-GP may result in further improvement in HRQoL for hemophilia A patients. The safety and efficacy of N8-GP have been evaluated in children, adolescents, and adults with severe hemophilia A in two multinational clinical phase III trials (pathfinder ${ }^{\text {TM}} 5$ and pathfinder $\left.{ }^{\mathrm{TM}} 2\right) .{ }^{12,13}$ In the pathfinder ${ }^{\mathrm{TM}} 5$ trial, the median annualized bleeding rate (ABR) was 1.95 , with $42.6 \%(n=29)$ of the subjects reporting no bleeds while on N8-GP prophylaxis. ${ }^{12}$ In the pathfinderTM 2 trial, the median ABR was 1.18 among those on N8-GP prophylaxis, with $40 \%(\mathrm{n}=70)$ reporting no bleeds. ${ }^{13}$ Both trials demonstrated that N8-GP had a favorable safety profile and was effective in preventing bleeds in patients with severe hemophilia A. ${ }^{12,13} \mathrm{HRQoL}$ was a secondary endpoint in both trials. It was hypothesized that there would be improvements in patients' HRQoL and increased treatment satisfaction (TS), as N8-GP extends the duration of coverage, which results in less bleeds, and requires fewer injections. The changes in HRQoL and TS in individuals with hemophilia A who received N8-GP within these trials are presented in this article.

\section{Materials and methods}

\section{Study design and patient population}

PathfinderTM5 (NCT01731600) was a phase III, multicenter, multinational, open-label single-arm trial. Patients enrolled in pathfinder ${ }^{\mathrm{TM}} 5$ were $<12$ years of age, with severe hemophilia A ( $<1 \%$ FVIII), had no history of inhibitors, and had been previously treated with FVIII products. Subjects in pathfinder ${ }^{\mathrm{TM}} 5$ were followed for 26 weeks and received a fixed dose of N8-GP via intravenous injection twice weekly. A total of 68 patients were included in pathfinder ${ }^{\mathrm{TM}} 5 ; 20$ were aged $\leq 4$ years, 23 were aged $4-7$ years, and 25 were aged $8-11$ years.

PathfinderTM2 (NCT01480180) was a phase III, multicenter, multinational, open-label, non-randomized trial. Patients enrolled in pathfinder ${ }^{\mathrm{TM}} 2$ were $\geq 12$ years of age with severe hemophilia A ( $<1 \%$ FVIII), had no history of inhibitors and had been previously treated with FVIII products. Patients were allocated to either the on-demand treatment arm (exposure days [ED]; Mean=55.2 [SD=35.6], range $=14-146$ days) or prophylaxis treatment arm (every 4 days) of N8-GP at the discretion of the investigator, and were followed between 6 and 27 months. A total of 186 patients were included in pathfinder ${ }^{\mathrm{TM}} 2$; two were aged 12 years, 16 were aged $13-16$ years, and 168 were adults aged $\geq 17$ years.

Both trials were approved by relevant independent ethics committees, institutional review boards, regulatory authorities, and conducted in accordance with the Declaration of Helsinki and Good Clinical Practice. All patients (adults or children who are able to provide consent) or their legally authorized representatives (children who are unable to provide consent) provided written informed consent before any trial-related activities. Both trials consisted of a main phase and an extension phase. As the extension phase is still ongoing, only the results of the main phase are reported here. The questionnaires were completed at two timepoints: prior to treatment with N8-GP and at the end of the main phase of each of the trials (pathfinder ${ }^{\mathrm{TM}} 5$ at 26 weeks and pathfinder ${ }^{\mathrm{TM}} 2$ at 76 weeks).

\section{Patient-reported outcomes (PRO) and observer-reported outcomes (ObsRO) questionnaires}

The Haemo-QoL and Haem-A-QoL are disease-specific HRQoL tools that have been validated in hemophilia patients of different ages. ${ }^{14,15}$ The Haemo-QoL I (ages 4-7 years) consists of 21 items covering eight domains; the Haemo-QoL II (ages 8-12 years) consists of 64 items covering 10 domains, and the Haemo-QoL III (13-16 years) consists of 77 items covering 12 domains. For each age group version, there is a child and a parent proxy version available. The Haem-A-QoL (used in patients ages $\geq 17$ years) consists of 46 items covering 10 domains. A total score and domain scores range from $0-100$, with lower scores indicating a better hemophiliarelated QoL. Domain and content for each version of the 
HRQoL questionnaires (Haemo-QoL and Haem-A-QoL) are presented in Table $\mathrm{S} 1$.

The Hemo-Sat questionnaire is an instrument designed specifically to assess TS in patients with hemophilia. HemoSat has two versions: the Hemo-Sat ${ }_{\mathrm{A}}$ (a version for adults aged $\geq 17$ years) and Hemo-Sat ${ }_{\mathrm{p}}$ (a version for parents of children with hemophilia who are aged $<17$ years). ${ }^{15-17}$ The Hemo-Sat ${ }_{\mathrm{A}}$ consists of 34 items covering six domains. The Hemo-Sat ${ }_{\mathrm{P}}$ measures the satisfaction with their child's treatment and includes the same items and domains as the Hemo-Sat ${ }_{\mathrm{A}}$, but with one additional item in the "ease and convenience" domain. Each domain score ranges from 0-100, with lower scores indicating a higher level of hemophilia TS.

\section{Statistical analysis}

Each trial was analyzed separately. Within each trial, the analyses were separated by age groups according to the recommended age of the respective questionnaire version. In pathfinder ${ }^{\mathrm{TM}} 2$, two patients were excluded from the analyses, as they took the Haemo-QoL II at baseline (aged 12) and the Haemo-QoL III (age 13) at the end of the main phase, thus a change in score could not be computed for these patients. Therefore, these patients were excluded from our analyses. Patients in pathfinder ${ }^{\mathrm{TM}} 2$ who started the trial with ondemand treatment, but switched to prophylaxis treatment, were included in both treatment groups in the demographic characteristics analyses and only included in the prophylaxis group for the HRQoL and TS analyses. Descriptive statistics were applied to examine the change in PRO and ObsRO scores from baseline to the end of the main phase of the trials. Responder analyses were performed using previously defined Haemo-QoL/Haem-A-QoL responder thresholds that were developed using a distribution-based method. ${ }^{18}$ Within the adult group of pathfinder ${ }^{\mathrm{TM}} 2$, the analyses were also performed according to treatment arm (on demand and prophylaxis), with a non-parametric signed-rank test to compare the change from baseline to end of main phase of the trial with a statistical significance threshold set at 5\%. Categorical values were presented as absolute and relative frequencies, while continuous variables were presented as means (standard deviations). All data processing and analyses were performed using SAS software for Windows version 9.4 (SAS Institute, Inc., Cary, NC, USA).

\section{Results}

\section{Study population}

Table 1 presents the description of patient characteristics at baseline, and Table 2 presents the completion rate of each $\mathrm{PRO} / \mathrm{ObsRO}$ questionnaire in both trials. Not all patients completed the PRO questionnaires at baseline, and some patients did not fill in the questionnaires at the end of the main phase resulting in a lower number of patients for whom HRQoL data were available at both baseline and end of main phase. Change in Haemo-QoL/Haem-A-QoL scores could be computed for seven children (30.4\%) and 14 parents $(60.9 \%)$ out of 23 children in age group $4-7$ years, 21 out

Table I Description of patient characteristics at baseline

\begin{tabular}{|c|c|c|c|c|}
\hline \multirow[t]{6}{*}{ Age group } & \multicolumn{2}{|l|}{ Pathfinder ${ }^{\mathrm{TM}} 5$} & \multicolumn{2}{|c|}{ Pathfinder ${ }^{\mathrm{TM}} \mathbf{2}$} \\
\hline & \multicolumn{2}{|l|}{$(\mathrm{N}=68)$} & \multicolumn{2}{|l|}{$(\mathrm{N}=186)^{\mathrm{a}}$} \\
\hline & Younger children & Older children & Patients & Patients \\
\hline & (0-5 years) & (6-II years) & ( $\geq 12$ years) & ( $\geq 18$ years) \\
\hline & \multirow[t]{2}{*}{$(\mathbf{N}=34)$} & \multirow[t]{2}{*}{$(\mathrm{N}=34)$} & Prophylaxis & On-Demand \\
\hline & & & $(N=175)$ & $(\mathrm{N}=12)$ \\
\hline Age, Mean (SD) & $3.0(1.3)$ & $8.9(1.7)$ & $30.6(12.5)$ & $39.8(13.9)$ \\
\hline Weight (Kg), Mean (SD) & I6.1 (3.4) & $34.1(11.5)$ & $75.0(14.4)$ & $73.5(12.8)$ \\
\hline \multicolumn{5}{|l|}{ Geographical region, n (\%) } \\
\hline Europe $^{\mathrm{b}}$ & $19(55.9)$ & $14(4 \mid .2)$ & $86(49.2)$ & $3(25.0)$ \\
\hline North America $^{c}$ & $12(35.3)$ & II (32.3) & $4 I(23.4)$ & $5(45.4)$ \\
\hline Other $^{d}$ & $3(8.8)$ & $9(26.5)$ & $48(27.4)$ & $4(36.4)$ \\
\hline \multicolumn{5}{|c|}{ Type of treatment prior to trial entry, $\mathrm{n}(\%)$} \\
\hline Prophylaxis & $31(91.2)$ & $34(100)$ & $149(85.1)$ & $0(0)$ \\
\hline On-Demand & $3(8.8)$ & $0(0)$ & $26(14.9)$ & $12(100)$ \\
\hline
\end{tabular}

Notes: a One patient changed treatment regimen from on-demand to prophylaxis at Visit 6 . Therefore, he is included in both the prophylaxis and on-demand arm, but only counted once in the total. 'Europe included Croatia, Denmark, France, Germany, Greece, Hungary, Italy, Lithuania, the Netherlands, Norway, Portugal, Russia, Spain, Sweden, Switzerland, Ukraine, and the UK. 'North America included Canada and the US. 'Other included Australia, Brazil, Israel, Japan, Malaysia, Republic of Korea, Taiwan, and Turkey. 
Table 2 Questionnaire completion rate

\begin{tabular}{|c|c|c|c|c|c|c|c|c|}
\hline \multirow[b]{2}{*}{ Age group } & \multicolumn{5}{|c|}{$\begin{array}{l}\text { Pathfinder }{ }^{\mathrm{TM}} 5 \\
(\mathrm{~N}=68)\end{array}$} & \multicolumn{3}{|c|}{$\begin{array}{l}\text { Pathfinder }{ }^{\mathrm{TM}} 2 \\
(\mathbf{N}=184)^{\mathrm{b}}\end{array}$} \\
\hline & $0-3$ years & \multicolumn{2}{|l|}{ 4-7 years } & \multicolumn{2}{|l|}{$8-11$ years } & \multicolumn{2}{|c|}{$13-16$ years } & $\geq 17$ years \\
\hline No. of patients enrolled in study & 20 & \multicolumn{2}{|l|}{23} & \multicolumn{2}{|l|}{25} & \multicolumn{2}{|l|}{16} & 168 \\
\hline \multicolumn{9}{|c|}{ Number of patients with completed PRO scores $n$ (\%) } \\
\hline \multirow[t]{2}{*}{ Respondent } & Parents & Children & Parents & Children & Parents & Children & Parents & Adults \\
\hline & \multicolumn{7}{|c|}{ Haemo-QoL } & Haem-A-QoL \\
\hline Baseline & - & $15(62.2)$ & $21(91.3)$ & $22(88.0)$ & $22(88.0)$ & $16(100)$ & $16(100)$ & $166(98.8)$ \\
\hline End of main phase & - & $13(56.5)$ & $14(60.9)$ & $21(84.0)$ & $21(84.0)$ & $10(62.5)$ & $9(56.3)$ & $165(98.2)$ \\
\hline \multirow[t]{2}{*}{ Change in score ${ }^{a}$} & - & $7(30.4)$ & $14(60.9)$ & $21(84.0)$ & $21(84.0)$ & $10(62.5)$ & $9(56.3)$ & $163(97.0)$ \\
\hline & \multicolumn{7}{|c|}{ Hemo-Sat $_{\mathrm{p}}$} & Hemo-Sat $_{A}$ \\
\hline Baseline & $19(95.0)$ & - & $20(87.0)$ & - & $22(88.0)$ & - & $10(62.5)$ & $167(99.4)$ \\
\hline End of main phase & $16(80.0)$ & - & $18(78.3)$ & - & $21(84.0)$ & - & $9(56.3)$ & $163(97.0)$ \\
\hline Change in scores ${ }^{\mathrm{a}}$ & $16(80.0)$ & - & 17 (73.9) & - & $21(84.0)$ & - & $4(25.0)$ & $162(96.4)$ \\
\hline
\end{tabular}

Notes: ${ }^{2}$ Some patients had a missing baseline score or end of main phase score, therefore a change in score was not able to be computed for these patients. ${ }^{\mathrm{b}} \mathrm{T}$ wo patients who were 12 years old in pathfinder ${ }^{\mathrm{TM}} 2$ were excluded from the analyses as they completed the Haemo-QoL II at baseline and Haemo-QoL III at the end of the main phase and a change of score cannot be computed. The Hemo-Sat questionnaire is an instrument designed specifically to assess TS in patients with hemophilia. The Hemo-Sat ${ }_{A}$ consists of 34 items covering six domains. The Hemo-Sat ${ }_{\mathrm{p}}$ (a version for parents of children with hemophilia who are aged $<17$ years) it measures the satisfaction with their child's treatment and includes the same items and domains as the Hemo-Sat ${ }_{A}$, but with one additional item in the "ease and convenience" domain.

Abbreviations: PRO, patient-reported outcomes; QoL, quality-of-life.

of 25 children and parents (84\%) in age group $8-11$ years; from all enrolled patients in pathfinder ${ }^{\mathrm{TM}} 2$ change in Haemo-QoL/Haem-A-QoL scores could be computed for 10 adolescents $(62.5 \%)$ and nine parents $(56.3 \%)$ out of 16 in the age group $13-16$ years and 163 out of 168 adults $(97.0 \%)$. Change in Hemo-Sat ${ }_{\mathrm{p}}$ scores could be computed for 54 parents of patients (79.4\%) across all age groups in pathfinder ${ }^{\mathrm{TM}} 5$, and four parents of patients (40\%) of 13-16 years in pathfinder ${ }^{\mathrm{TM}} 2$. Change in Hemo-Sat ${ }_{\mathrm{A}}$ scores could be computed for 162 of 168 (96.4\%) adults in pathfinder ${ }^{\mathrm{TM}} 2$. All pediatric patients in pathfinder ${ }^{\mathrm{TM}} 5$ and all the adolescents aged 13-16 years in pathfinder ${ }^{\mathrm{TM}} 2$ were on prophylaxis during the trial. Among the adults, 11 received on-demand treatment and 157 received prophylaxis in pathfinder ${ }^{\mathrm{TM}} 2$, including one patient who switched from on-demand treatment to prophylaxis treatment at visit 6 .

\section{HRQoL in pathfinder ${ }^{\mathrm{TM}} 2$}

As shown in Table 3, baseline "total Haemo-QoL III" scores in the 13-16 year age group were low, indicating a good overall hemophilia-specific HRQoL, according to both the adolescents and their parents. Adolescents also reported low domain scores for across each domain at baseline, with the exception of "Perceived Support". Mean change in "total Haemo-QoL" scores yielded no change in HRQoL according to the adolescents and their parents. Adolescents had no changes in any domain, while parents reported improvements in "Others" and "Physical Health" domains and declines in "Perceived Support" and "Friend" domains. According to the "total Haemo-QoL III" responder threshold, ${ }^{18}$ overall HRQoL improvement was observed for $12.5 \%$ of adolescents and $18.8 \%$ of their parents.

As shown in Table 4, adults in the prophylaxis arm had a lower "total Haem-A-QoL" score at baseline when compared to adults in the on-demand arm. Moderate baseline Haem-A-QoL scores were observed in the "Physical Health", "Feeling", "View", "Sport", and "Future" domains for the on-demand arm and "Sport" domain for the prophylaxis arm. There were no significant differences in change in scores between the two treatment arms. For the on-demand arm, there were no significant within group changes for any of the Haem-A-QoL scores. However, most scores trended towards improvement (negative change in scores). Within the prophylaxis arm, there were statistically significant improvements for the "Physical Health" $(P<0.001)$, "Work" $(P=0.003)$, "Feeling" $(P=0.016)$, and "View" $(P=0.048)$ domains and the "total HAEM-A-QOL" score ( $P=0.002)$. In total, $54.5 \%$ of adults in the on-demand arm and $24.2 \%$ of adults in the prophylaxis arm improved in HRQoL according to the "total Haem-A-QoL" responder threshold. ${ }^{18}$

\section{HRQoL in pathfinder ${ }^{\mathrm{TM}} 5$}

As shown in Table 3, children and their parents in the 4-7 year age group reported a relatively good overall hemophilia-specific HRQoL at baseline, based on the mean "total Haemo-QoL I" scores. Most of the baseline Haemo-QoL I domain scores were also on the lower end of the scale (indicative of a good HRQoL), except for "Family" according to both the children and their parents, "Treatment" according to the children, and "Preschool/ 
Table 3 Mean (SD) and percentage of responders for Haemo-QoL scores in children and adolescents

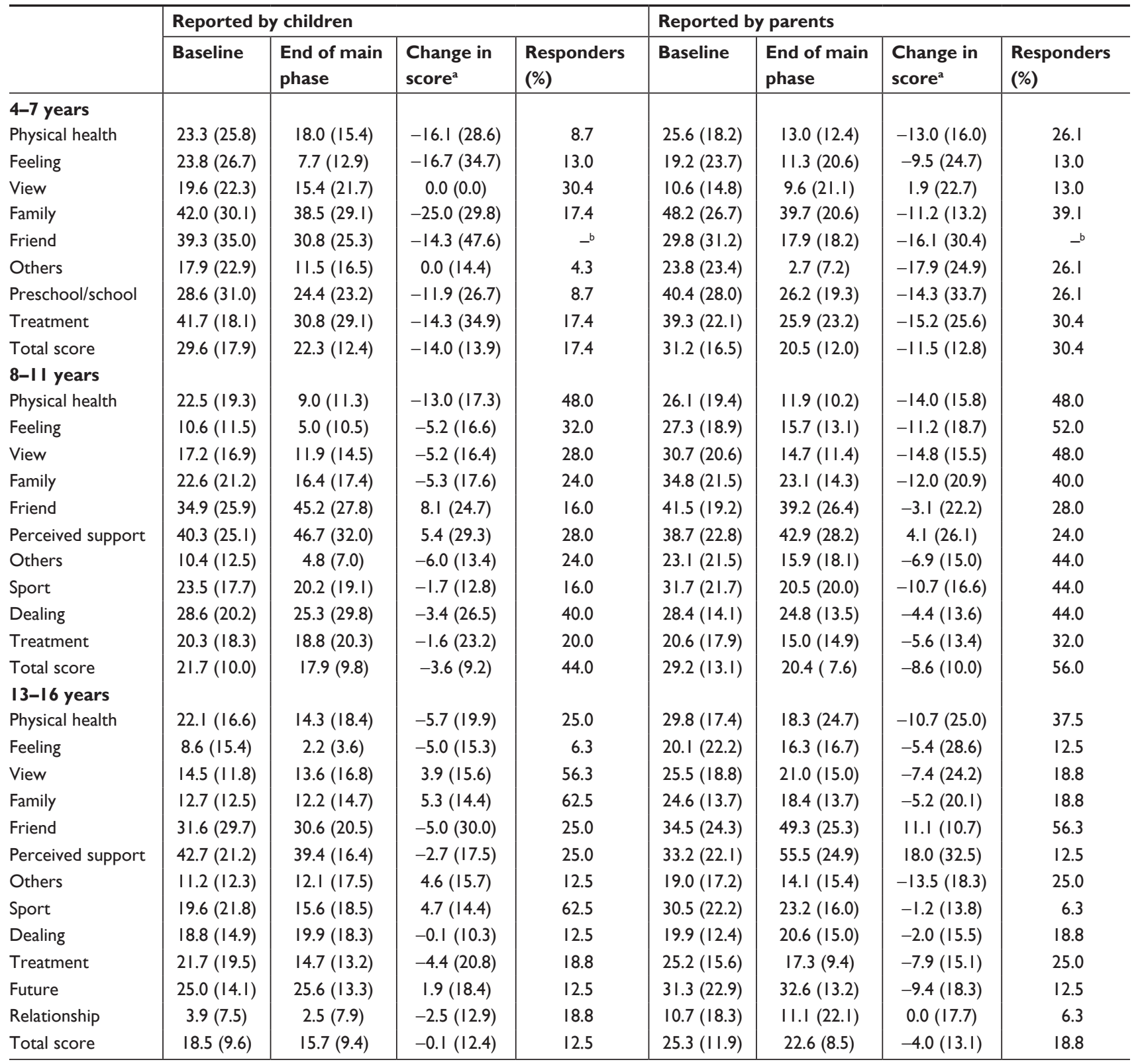

Notes: aSome patients had a missing baseline score or end of main phase score, therefore a change in score was not able to be computed for these patients; a negative change in score implies an improvement in HRQoL. 'bingle-item dimension not enabling the calculation of the internal consistency coefficient, thus Santagostino et al ${ }^{18}$ did not calculate a threshold for this domain.

Abbreviation: HRQoL, health-related quality-of-life.

School" according to the parents. Mean "total Haemo-QoL I" change score demonstrated a marked improvement (mean score exceeding a previously defined responder threshold $)^{18}$ in HRQoL as reported by the children and their parents. Children showed marked improvements in "Family", "Feeling", and "Physical Health" domains; while parents reported marked improvements in "Others", "Physical Health", and "Family" domains. According to the "total Haemo-QoL I" responder threshold, ${ }^{18}$ overall HRQoL improvement was observed for $17 \%$ of children and $30 \%$ of their parents.
In the 8-11 year age group, children and their parents reported a relatively good overall hemophilia-specific $\mathrm{HRQoL}$ at baseline (Table 3). There were low mean domain scores at baseline for all domains except for the "Friend" domain according to the parents. Mean change for the "total HaemoQoL II" score demonstrated minimal change in HRQoL as reported by the children, and marked improvement in HRQoL by their parents. Children showed marked improvements in the "Physical Health" domain; while trending towards improvements in other domains. A modest decline was found in their relationship with their "Friends" relating to hemophilia. 
Table 4 Mean (SD) and percentage of responders for Haem-A-QoL scores in adults (aged $\geq 17$ )

\begin{tabular}{|c|c|c|c|c|c|c|c|c|}
\hline \multirow[t]{3}{*}{ Domain } & \multicolumn{8}{|c|}{$\begin{array}{l}\text { Adult analysis set } \\
(\mathrm{N}=166)\end{array}$} \\
\hline & \multicolumn{2}{|l|}{ Baseline } & \multicolumn{2}{|c|}{ End of main phase } & \multicolumn{2}{|c|}{ Change in score ${ }^{a}$} & \multicolumn{2}{|c|}{ Responders (\%) } \\
\hline & $\begin{array}{l}\text { On-Demand } \\
(\mathbf{N}=I I)\end{array}$ & $\begin{array}{l}\text { Prophylaxis } \\
50 \text { IU/KG } \\
(\mathbf{N}=\mid 55)\end{array}$ & $\begin{array}{l}\text { On-Demand } \\
(\mathbf{N}=I I)\end{array}$ & $\begin{array}{l}\text { Prophylaxis } \\
50 \text { IU/KG } \\
(\mathrm{N}=154)\end{array}$ & $\begin{array}{l}\text { On-Demand } \\
(\mathrm{N}=\mathrm{II})\end{array}$ & $\begin{array}{l}\text { Prophylaxis } \\
50 \text { IU/KG } \\
(\mathrm{N}=\mid \mathbf{5 2})\end{array}$ & $\begin{array}{l}\text { On-Demand } \\
(\mathrm{N}=\mathrm{II})\end{array}$ & $\begin{array}{l}\text { Prophylaxis } \\
50 \text { IU/KG } \\
(\mathrm{N}=152)\end{array}$ \\
\hline Physical health & $54.1(20.6)$ & $38.6(26.4)$ & $46.8(24.5)$ & $30.5(23.8)$ & $-7.3(18.5)$ & $-8.4(\mid 8.1)^{* *}$ & 45.5 & 43.3 \\
\hline Feeling & $40.9(28.1)$ & $23.6(23.6)$ & 34.7 (3I.4) & $20.0(22.8)$ & $-6.3(16.5)$ & $-3.5(17.7)^{*}$ & 36.4 & 27.4 \\
\hline View & $51.4(16.5)$ & $35.5(21.0)$ & $45.8(25.6)$ & $32.9(21.4)$ & $-5.6(18.1)$ & $-2.9(17.9)^{*}$ & 9.1 & 11.5 \\
\hline Sport & $54.0(21.1)$ & 49.4 (27.2) & 53.1 (28.7) & $50.8(28.6)$ & $-1.3(24.0)$ & $0.7(17.4)$ & 27.3 & 10.2 \\
\hline Work & $36.7(19.6)$ & $21.2(21.9)$ & 31.7 (2I.5) & I5.7 (I8.7) & $-6.3(28.3)$ & $-4.7(I 7.7)^{*}$ & 18.2 & 15.9 \\
\hline Dealing & $25.0(16.2)$ & $17.2(18.0)$ & $18.2(18.2)$ & $17.0(20.5)$ & $-6.8(14.4)$ & $0.1(20.8)$ & 27.3 & 17.2 \\
\hline Treatment & $37.5(24.1)$ & $31.1(17.2)$ & 38.1 (20.4) & $29.6(17.3)$ & $0.6(20.4)$ & $-1.6(12.4)$ & 27.3 & 19.7 \\
\hline Future & $40.5(16.2)$ & $36.7(22.6)$ & $40.9(30.0)$ & $36.7(22.3)$ & $0.5(18.8)$ & $-0.2(15.4)$ & 9.1 & 12.7 \\
\hline Family planning & I5.5 (24.9) & $19.3(27.3)$ & $5.2(10.0)$ & $19.4(27.3)$ & $-6.6(15.2)$ & I.0 (20.4) & 9.1 & 10.8 \\
\hline Partnership & $25.0(28.4)$ & I4.4 (23.4) & I7.8 (25.7) & I4.5 (23.6) & $-7.2(12.4)$ & $0.1(17.5)$ & 27.3 & 15.3 \\
\hline Total score & $40.6(16.0)$ & $30.8(16.5)$ & $37.4(19.2)$ & $28.7(16.4)$ & $-3.1(10.3)$ & $-2.3(8.9)^{*}$ & 54.5 & 24.2 \\
\hline
\end{tabular}

Notes: aSome patients had a missing baseline score or end of main phase score, therefore a change in score was not able to be computed for these patients; a negative change in score implies an improvement in HRQoL. $P$-values indicate significance within change using the signed-rank test: $* P<0.05$, $* * P<0.0001$.

Abbreviation: HRQoL, health-related quality-of-life.

Both children and their parents had a modest decline in the "Perceived support" domain. Parents reported marked improvements in the "View", "Physical Health", "Family", and "Feeling" domains; while trending towards improvements in other domains. When applying the "total Haemo-QoL II" score responder threshold, ${ }^{18} 44.0 \%$ of children and $56.0 \%$ of parents have reported improvements in overall HRQoL.

\section{Treatment satisfaction}

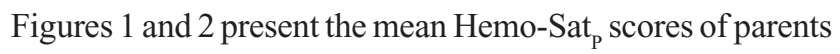
in pathfinder ${ }^{\mathrm{TM}} 5$ and pathfinder ${ }^{\mathrm{TM}} 2$, respectively, at baseline and the end of the main phase, and show the mean change $\left(\Delta\right.$ Hemo-Sat $\left._{\mathrm{p}}\right)$ in parents who completed the Hemo-Sat ${ }_{\mathrm{p}}$ at both baseline and the end of the main phase.
Parents reported high levels of TS at baseline visits in both trials, which indicates that they had a high level of TS with the treatment received prior to entering the trial. At the end of the main phase visits, mean Hemo-Sat ${ }_{\mathrm{p}}$ scores were also low for all age groups in both trials, indicating high levels of TS with N8-GP. The mean change in Hemo-Sat ${ }_{\mathrm{P}}$ scores indicated that parents had higher satisfaction or a similar level of satisfaction with N8-GP as compared to the treatment received prior to entering the trial.

Figure 3 presents the mean baseline, end-of-treatment, and change Hemo-Sat ${ }_{A}$ scores of adults in pathfinder ${ }^{\mathrm{TM}} 2$ treated on-demand, and Figure 4 presents the mean baseline, endof-treatment, and change Hemo-Sat ${ }_{\mathrm{A}}$ scores of adults treated prophylactically. Similar to the parents, adults reported high

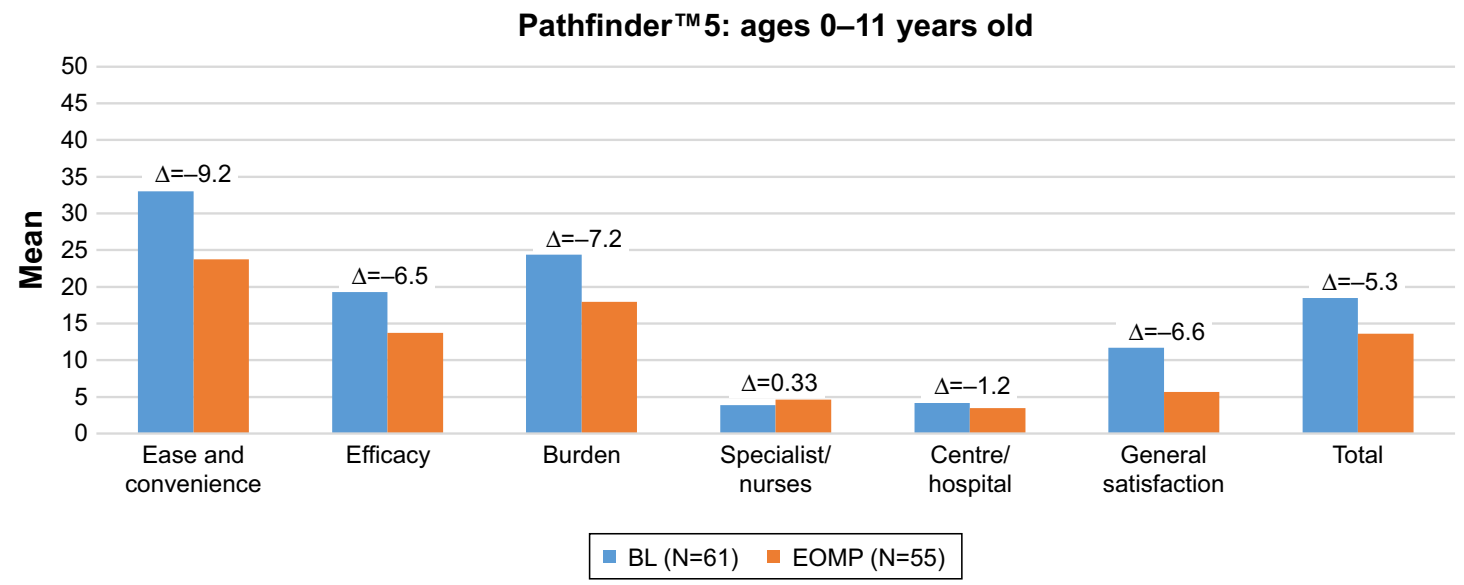

Figure I Description of Hemo-Sat $t_{p}$ scores at each visit (baseline and end of main phase) and mean change in scores during pathfinder ${ }^{\mathrm{TM}} 5$.

Notes: The Hemo-Sat questionnaire is an instrument designed specifically to assess TS in patients with hemophilia. The Hemo-Sat ${ }_{p}(a$ version for parents of children with hemophilia who are aged $<17$ years).

Abbreviations: BL, baseline; EOMP, end of main phase. 


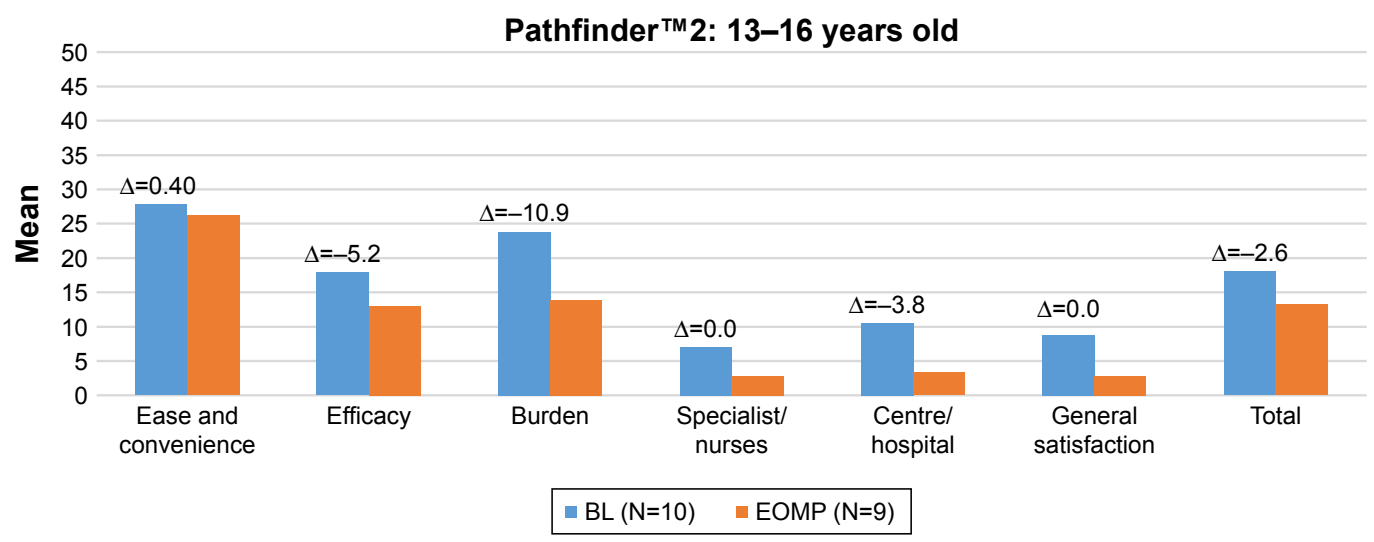

Figure 2 Description of Hemo-Sat ${ }_{\mathrm{p}}$ scores at each visit (baseline and end of main phase) and mean change in scores during pathfinder ${ }^{\mathrm{TM}} 2$.

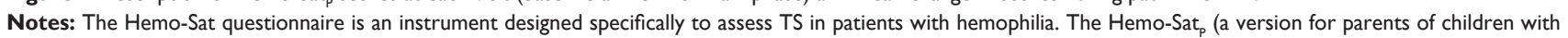
hemophilia who are aged $<17$ years).

Abbreviations: BL, baseline; EOMP, end of main phase.

levels of satisfaction at the baseline visits and at the end of the main phase visits. For adults, the level of satisfaction between those in the on-demand arm and those in the prophylaxis arm were comparable. When examining the change in Hemo-Sat scores, mean changes in all domains indicated that TS was either comparable or higher with N8-GP compared to the treatment received prior to entering the pathfinder ${ }^{\mathrm{TM}}$ trial.

\section{Discussion}

The objective of the analysis reported in this article was to investigate the HRQoL and treatment satisfaction of children, adolescents, and adults with severe hemophilia A treated with N8-GP in the pathfinder ${ }^{\mathrm{TM}} 5$ and pathfinder ${ }^{\mathrm{TM}} 2$ trials using disease-specific, age-appropriate, validated questionnaires. ${ }^{15,16}$

At baseline, all patients across trials reported a good overall HRQoL as indicated by their total Haemo-QoL/ Haem-A-QoL scores. Thus, there was generally little room for improvement for any group. Improvement in "Physical Health" and overall hemophilia-specific HRQoL was observed in pediatric patients aged 4-7 and 8-11 and adults $\geq 17$ years treated with N8-GP prophylaxis during the trials. The adolescents aged 13-16 years reported that their hemophilia-specific HRQoL was maintained, while their parents reported improvements in their child's "Physical Health". Trends in psychologic/social domains were less consistent across age groups; however, patients across age groups reported improvements in "Feeling". Adults reported improvements in participating in work/school activities by the end of the trial. These findings highlight the potential benefits beyond physical health of N8-GP when administered prophylactically.

Santagostino et al ${ }^{18}$ investigated the HRQoL of patients with severe hemophilia A treated with turoctocog alfa for a mean duration of 6 months among patients aged 12-65 years (guardian $^{\mathrm{TM}} 1$ ) or for a mean duration of 4.5 months among

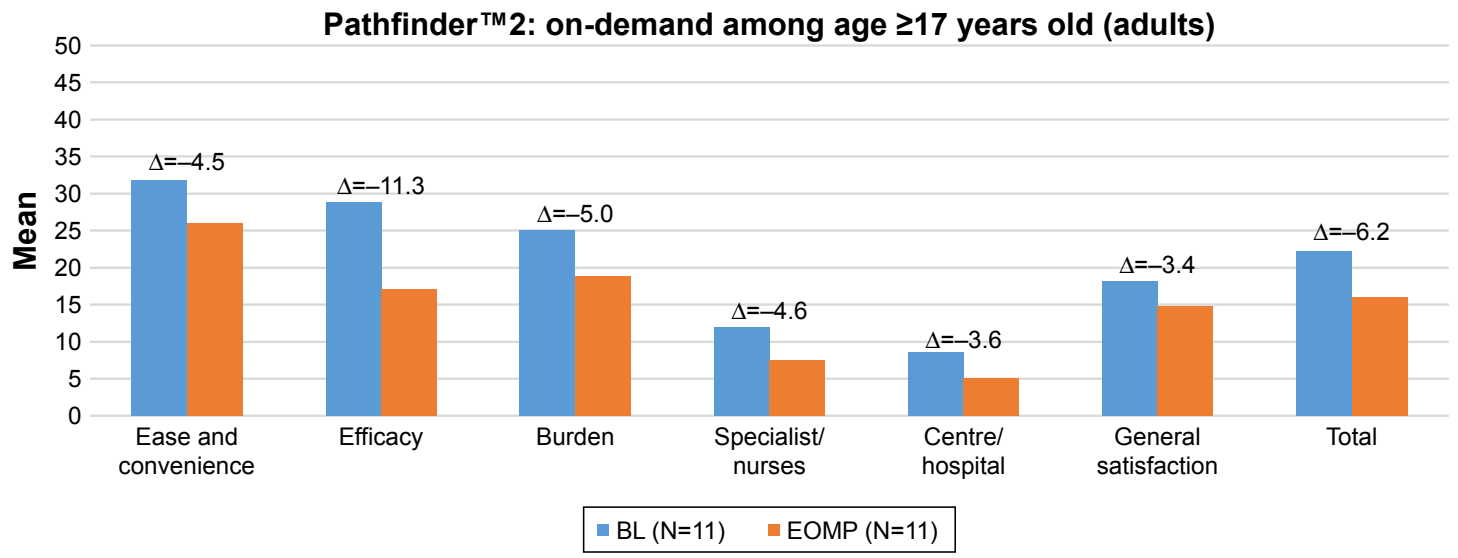

Figure 3 Description of Hemo-Sat ${ }_{A}$ scores at each visit (baseline and end of main phase) and mean change in scores for adults treated on-demand during pathfinder ${ }^{\mathrm{TM}} 2$. Notes: The Hemo-Sat questionnaire is an instrument designed specifically to assess TS in patients with hemophilia. The Hemo-Sat is (a version for adults aged $\geq 17$ years). Abbreviations: BL, baseline; EOMP, end of main phase. 


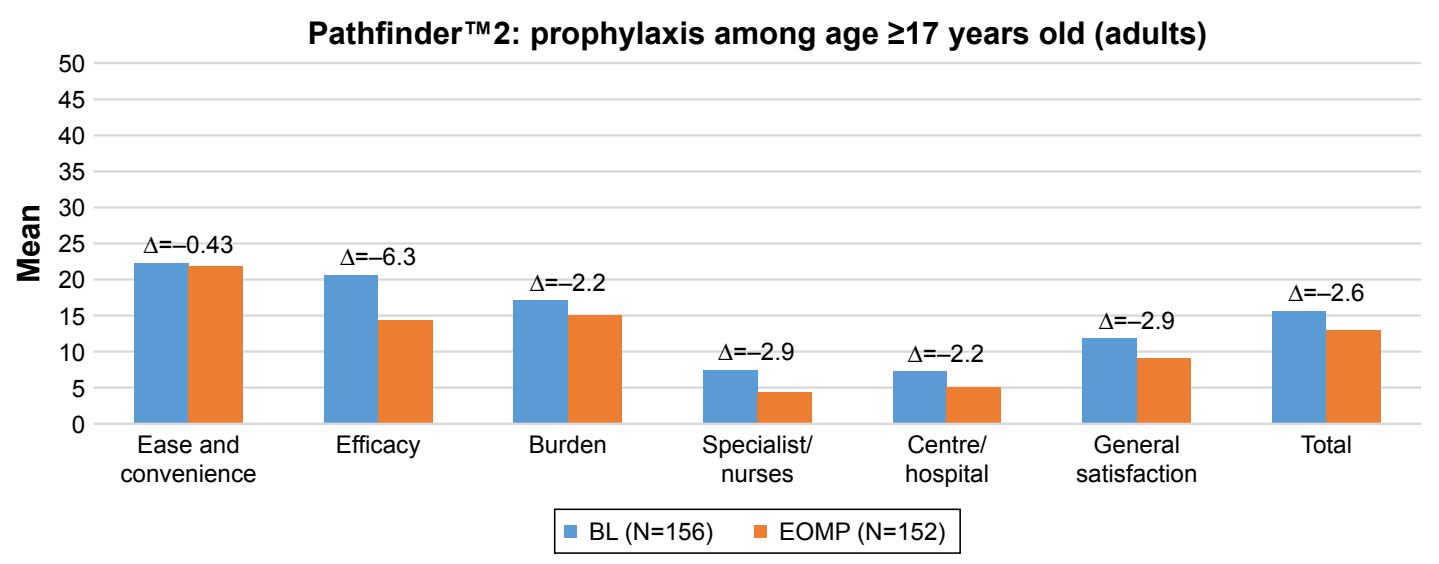

Figure 4 Description of Hemo-Sat ${ }_{A}$ scores at each visit (baseline and end of main phase) and mean change in scores for adults treated prophylactically during pathfinder ${ }^{\mathrm{TM}} 2$. Notes: The Hemo-Sat questionnaire is an instrument designed specifically to assess TS in patients with hemophilia. The Hemo-Sat ${ }_{A}$ is a version for adults aged $\geq 17$ years). Abbreviations: BL, baseline; EOMP, end of main phase.

patients aged $0-11$ years (guardian ${ }^{\mathrm{TM}} 3$ ). The patients who participated in these trials had similar overall HRQoL, as measured by the total Haemo-QoL/Haem-A-QoL score at baseline, compared to patients in the pathfinder ${ }^{\mathrm{TM}}$ trials at baseline. Both the guardian ${ }^{\mathrm{TM}}$ and the pathfinder ${ }^{\mathrm{TM}}$ trials showed similar trends of improvements or maintained overall HRQoL during the course of their respective trials for all age groups. The only exception was that children aged 4-7 years and their parents in the guardian ${ }^{\mathrm{TM}} 3$ trial reported no change in the overall HRQoL during the trial, while both children and their parents reported substantial improvement in the overall HRQoL in the pathfinder ${ }^{\mathrm{TM}} 5$ trial. In the guardian ${ }^{\mathrm{TM}}$ and pathfinder ${ }^{\mathrm{TM}}$ trials, patients entered their respective trial with a good HRQoL, which leaves little room for improvement in HRQoL during the duration of the trial.

In the A-LONG study in which adult hemophilia A patients were treated with another EHL product, a recombinant factor VIII FC fusion protein on a prophylactic (weekly prophylaxis or individualized prophylaxis) or episodic (as needed) regimen, significant HRQoL changes between baseline and 28 weeks follow-up were found only for the individualized prophylaxis arm in the Haem-A-QoL "Physical Health" domain and the "Total Score". ${ }^{19}$ In contrast in the pathfinder ${ }^{\mathrm{TM}} 2$ trial, significant mean HRQoL changes between baseline and the end of the main phase were seen in the prophylaxis arm for the Haem-A-QoL domains "Physical Health", "Feeling", "View", "Work", and the "Total Score".

Parents of children and adolescents as well as adult patients reported high levels of TS at baseline, indicating high satisfaction with treatment received prior to entering the trial. Similarly, they showed high levels of TS with N8-GP, as measured by the Hemo-Sat scores at the end of the main phase. When examining the change in Hemo-Sat scores, the TS levels were either comparable between N8-GP and the previous treatment or higher for N8-GP, suggesting potentially higher TS with the new drug. However, caution should be applied when interpreting these findings, as previous works have found that the expectation of treatment received prior to entering a trial may not match up with the expectation of the treatment received during the trial. ${ }^{20,21}$ The claim of increased TS for N8-GP, however, can be supported with the low median $\mathrm{ABR}$ reported for pathfinder ${ }^{\mathrm{TM}} 5$ and for pathfinder ${ }^{\mathrm{TM}} 2 .{ }^{12,13}$

Several limitations of the analysis should be highlighted. The study of HRQoL within the pathfinder ${ }^{\mathrm{TM}}$ clinical trials is hindered by the lack of randomization and blinding which results in the loss of a comparator arm and potential bias based on preconceived ideas of efficacy. Small sample sizes and missing data are also problematic, especially in the younger age groups in the pathfinder ${ }^{\mathrm{TM}}$ trials.

It has been previously shown that age is a predictor of HRQoL among individuals with severe hemophilia, where older individuals are more likely to report poorer HRQoL on the generic 36-Item Short Form Survey (SF-36) and European Quality of Life 5 dimensions (EQ-5D). ${ }^{22,23}$ In this study, HRQoL was analyzed separately for each age group, as individual's experiences vary dependent on age. This was reflected by the multiple age-specific versions of the Haemo-QoL/ Haem-A-QoL. The association between change in HRQoL and change in ABR could not be completed due to the absence of baseline ABR data. Finally, the analyses of HRQoL are based on a relatively short or limited exposure with N8-GP (26 weeks for pathfinder ${ }^{\mathrm{TM}} 5$ and up to 76 weeks for pathfinder ${ }^{\mathrm{TM}} 2$ ).

Despite these challenges, there is limited knowledge on HRQoL among patients with hemophilia A, especially 
in the youngest subgroups. Therefore, even with a limited sample size, this study contributes to the understanding of the HRQoL of hemophilia patients, specifically focusing on the potential differences in HRQoL in patients receiving EHL FVIII replacement therapy. Further longitudinal data may be obtained based on the extension phase of these trials to understand the long-term usage of EHL FVIII replacement therapies. As newer EHL therapies entering the market aim to reduce the number of injections and to increase trough levels, future analyses can examine if the frequency of dosing (bi-weekly vs every 4 days) or trough level impact HRQoL.

\section{Conclusion}

Treatment with N8-GP resulted in a good disease-specific HRQoL of children, adolescents, and adults with severe hemophilia A. While most patients entered their respective trials with a good disease-specific HRQoL, the HRQoL of patients was either maintained or further improved when treated with N8-GP. Adults and parents of children and adolescents further reported high levels of treatment satisfaction with N8-GP.

\section{Data sharing statement}

On reasonable request, the subject level analysis data sets for the research presented in the publication are available by contacting Andrea Landorph. Individual participant data will be shared in data sets in a de-identified/anonymized format. The study protocol and redacted Clinical Study Report (CSR) will be available according to Novo Nordisk data sharing commitments. The accessibility data will be available permanently after research completion and approval of product and product use in both the EU and US.

\section{Ethics approval}

Both trials were approved by relevant independent ethics committees, institutional review boards, regulatory authorities (Table S2) and conducted in accordance with the Declaration of Helsinki and Good Clinical Practice. Both trials were registered in ClinicalTrials.gov (NCT01731600 and NCT01480180).

\section{Acknowledgments}

This study was funded by Novo Nordisk A/S Denmark. The authors thank all participating investigators, patients, and trial staff. The authors also thank Jeremy Lambert (Mapi) for medical writing assistance and editorial support in the manuscript preparation and Frank Driessler (Novo Nordisk) for their critical review during manuscript preparation.

\section{Author contributions}

LJR, SK, JO, and HT were principal investigators and enrolled and cared for patients during the trial. TPP conducted the analyses of the data, interpreted the data, and wrote and revised the manuscript. AL provided clinical input for the data analysis. XYL provided input for the analysis and interpretation of PRO data. SvM is the developer of the Haemo-QoL, Haem-A-QoL, and Hemo-Sat questionnaires and provided input for the analysis and interpretation of PRO data. All authors contributed to data analysis, drafting and revising the article, gave final approval of the version to be published, and agree to be accountable for all aspects of the work.

\section{Disclosure}

LJR was a paid consultant for Bayer, CSL Behring, Genentech, and Green Cross Inc. LJR also reports personal fees from Bayer, personal fees from Roche, outside the submitted work. SK has received grant/research support from Bayer, Bioverativ, Daiichi Sankyo, Grisfols, and Novo Nordisk, and served on speaker/advisory boards for Bayer, Bioverativ, and Novo Nordisk. SK also reports research support as the local principal investigation from Bayer, Bioverativ, Daiichi Sankyo, Grisfols, and Novo Nordisk, and work on advisory boards for Bayer, Bioverativ, and Novo Nordisk. JO has received grant/research support from Novo Nordisk and Baxter, Bayer, Biotest, CSL Behring, Grifols, Octa-pharma, and Pfizer, outside the submitted work, and has received personal fees and acted as a speaker for Baxter, Bayer, Biogen Idec, Biotest, CSL Behring, Grifols, Novo Nordisk, Octapharma, Swedish Orphan Biovitrum, and Pfizer. JO also reports grants and personal fees from Bayer, grants and personal fees from Biotest, personal fees from Chugai, grants, personal fees from CSL Behring, personal fees from Grifols, grants and personal fees from Novo Nordisk, grants and personal fees from Octapharma, personal fees from Pfizer, personal fees from Roche, personal fees from SOBI, and grants and personal fees from Shire, outside the submitted work. HT has received honoraria for speaking or participated in scientific advisory boards or symposia from Baxalta/Shire, Bayer, Biogen, Bioverativ, Chugai Pharmaceutical, CSL Behring, Kaketsuken, Novo Nordisk, and Pfizer, and grants from CSL Behring. AL and XYL are employees of Novo Nordisk $\mathrm{A} / \mathrm{S}$. SvM is the developer of the HRQoL and treatment satisfaction questionnaires (Haemo-QoL, Haem-A-QoL and Hemo-Sat) used in the study and a consultant of Novo Nordisk. TPP was a paid consultant for Novo Nordisk A/S 
as an employee of ICON plc (formerly Mapi). The authors report no other conflicts of interest in this work.

\section{References}

1. Srivastava A, Brewer AK, Mauser-Bunschoten EP, et al. Guidelines for the management of hemophilia. Haemophilia. 2013;19(1):e1-e47. doi:10.1111/j.1365-2516.2012.02909.x

2. van Genderen FR, Fischer K, Heijnen L, et al. Pain and functional limitations in patients with severe haemophilia. Haemophilia. 2006;12(2):147-153. doi:10.1111/j.1365-2516.2006.01203.x

3. Witkop M, Guelcher C, Forsyth A, et al. Treatment outcomes, quality of life, and impact of hemophilia on young adults (aged 18-30 years) with hemophilia. Am J Hematol. 2015;90(Suppl 2):S3-S10. doi:10.1002/ ajh. 24220

4. Holstein K, von Mackensen S, Bokemeyer C, Langer F. The impact of bleeding disorders on the socioeconomic status of adult patients. Results of a comparative single centre cohort study. Hamostaseologie. 2017;99:99. doi:10.5482/HAMO-16-12-0047

5. Mannucci PM, Franchini M. Present and future challanges in the treatment of haemophilia: a clinician's perspective. Blood Transfusion. 2013;11(Suppl 4):s77-s81. doi:10.2450/2013.012s

6. Mahlangu J, Young G, Hermans C, Blanchette V, Berntorp E, Santagostino E. Defining extended half-life rFVIII - a critical review of the evidence. Haemophilia. 2018;24(3):348-358. doi:10.1111/hae.13438

7. du Treil S, Rice J, Leissinger CA. Quantifying adherence to treatment and its relationship to quality of life in a well-characterized haemophilia population. Haemophilia. 2007;13(5):493-501. doi:10.1111/j.1365-2516.2007.01526.x

8. Duncan N, Shapiro A, Ye X, Epstein J, Luo MP. Treatment patterns, health-related quality of life and adherence to prophylaxis among haemophilia A patients in the United States. Haemophilia. 2012;18(5): 760-765. doi:10.1111/j.1365-2516.2012.02813.x

9. Gringeri A, Lundin B, von Mackensen S, Mantovani L, Mannucci PM. A randomized clinical trial of prophylaxis in children with hemophilia A (the ESPRIT Study). J Thromb Haemost. 2011;9(4):700-710. doi:10.1111/j.1538-7836.2011.04214.x

10. Manco-Johnson MJ, Abshire TC, Shapiro AD, et al. Prophylaxis versus episodic treatment to prevent joint disease in boys with severe hemophilia. $N$ Engl J Med. 2007;357(6):535-544. doi:10.1056/ NEJMoa067659

11. Tiede A, Brand B, Fischer R, et al. Enhancing the pharmacokinetic properties of recombinant factor VIII: first-in-human trial of glycoPEGylated recombinant factor VIII in patients with hemophilia A. J Thromb Haemost. 2013;11(4):670-678. doi:10.1111/jth.12161
12. Meunier S, Alamelu J, Ehrenforth S, et al. Safety and efficacy of a glycoPEGylated rFVIII (turoctocog alpha pegol, N8-GP) in paediatric patients with severe haemophilia A. Thromb Haemost. 2017;117(9):1705-1713. doi:10.1160/TH17-03-0166

13. Giangrande P, Andreeva T, Chowdary P, et al. Clinical evaluation of glycoPEGylated recombinant FVIII: efficacy and safety in severe haemophilia A. Thromb Haemost. 2017;117(2):252-261. doi:10.1160/ TH16-06-0444

14. von Mackensen S, Bullinger M, Haemo-QoL Group. Development and testing of an instrument to assess the quality of life of children with haemophilia in Europe (Haemo-QoL). Haemophilia. 2004;10(Suppl 1): 17-25. doi:10.1111/j.1355-0691.2004.00875.x

15. von Mackensen S, Gringeri A. Quality of life in hemophilia. In: Preedy V, Watson R, editors. Handbook of Disease Burdens and Quality of Life Measures. New York, NY: Springer; 2010:1895-1920.

16. von Mackensen S, Gringeri A, Mantovani L. Development and validation of the first treatment satisfaction scale for adult haemophiliacs (Hemo-SatA). Haemophilia. 2004;10(Suppl 3):126.

17. von Mackensen S, Gringeri A, Skovlund S. Assessment of treatment satisfaction in patients with haemophilia-development and validation of the first disease-specific questionnaire (Hemo-SatA). $J$ Thromb Haemost. 2005;3(Suppl):1.

18. Santagostino E, Lentz SR, Busk AK, Regnault A, Iorio A. Assessment of the impact of treatment on quality of life of patients with haemophilia A at different ages: insights from two clinical trials on turoctocog alfa. Haemophilia. 2014;20(4):527-534. doi:10.1111/hae.12371

19. Wyrwich KW, Krishnan S, Auguste P, et al. Changes in healthrelated quality of life with treatment of longer-acting clotting factors: results in the A-LONG and B-LONG clinical studies. Haemophilia. 2016;22(6):866-872. doi:10.1111/hae.12987

20. Rofail D, Regnault A, Baladi J-F, Berdeaux G. Assessing treatment satisfaction during a product's lifecycle to facilitate market access: definitions, frameworks, and measurement. ISPOR Connect. 2010;16(3): $7-10$.

21. Shikiar R, Rentz AM. Satisfaction with medication: an overview of conceptual, methodologic, and regulatory issues. Value Health. 2004;7(2):204-215. doi:10.1111/j.1524-4733.2004.72252.x

22. Miners AH, Sabin CA, Tolley KH, Jenkinson C, Kind P, Lee CA. Assessing health-related quality-of-life in individuals with haemophilia. Haemophilia. 1999;5(6):378-385.

23. Gringeri A, von Mackensen S, Auerswald G, et al. Health status and health-related quality of life of children with haemophilia from six West European countries. Haemophilia. 2004;10(Suppl 1):26-33. 


\section{Supplementary materials}

Table SI Description of Haemo-QoL and Haem-A-QoL domains

\begin{tabular}{|c|c|c|c|c|}
\hline Domains & $\begin{array}{l}\text { Haemo-QoL-I } \\
\text { (4-7 years) }\end{array}$ & $\begin{array}{l}\text { Haemo-QoL-II } \\
\text { (8-12 years) }\end{array}$ & $\begin{array}{l}\text { Haemo-QoL-III } \\
\text { (13-16 years) }\end{array}$ & $\begin{array}{l}\text { Haem-A-QoL } \\
\text { ( } \geq 17 \text { years) }\end{array}$ \\
\hline Physical health & \multicolumn{4}{|c|}{ Related to the level of joint pain and other issues related to physical health } \\
\hline Feeling & \multicolumn{4}{|c|}{ Related to emotional wellbeing, including feeling worried, sad, lonely, etc., due to hemophilia } \\
\hline View & \multicolumn{4}{|c|}{ Related to the attitude toward others and the impact of hemophilia on ability to do things } \\
\hline Family & \multicolumn{3}{|c|}{ Related to the level of overprotection from parents and impact of hemophilia on family life } & - \\
\hline Friend & \multicolumn{3}{|c|}{ Related to relationship with friends and ability to talk with them about hemophilia } & - \\
\hline Others & \multicolumn{3}{|c|}{ Related to feeling different from others and the attitude and behavior of others } & - \\
\hline Perceived support & - & \multicolumn{2}{|c|}{$\begin{array}{l}\text { Related to consideration and understanding from others } \\
\text { in relation to hemophilia }\end{array}$} & - \\
\hline Dealing & - & \multicolumn{3}{|c|}{ Related to the recognition and control of symptoms, and acceptance of disease } \\
\hline Sport and preschool/school & \multicolumn{4}{|c|}{ Related to participating in different types of physical and leisure activities and intellectual activities in/outside school } \\
\hline Treatment & \multicolumn{4}{|c|}{$\begin{array}{l}\text { Related to the satisfaction with and acceptance of the treatment, healthcare management, and injection-related } \\
\text { constraints }\end{array}$} \\
\hline Future & \multicolumn{2}{|c|}{-} & \multicolumn{2}{|c|}{$\begin{array}{l}\text { Related to health and well-being in the future due to } \\
\text { hemophilia }\end{array}$} \\
\hline Relationships & \multicolumn{2}{|c|}{-} & \multicolumn{2}{|c|}{ Related to romantic partnership due to hemophilia } \\
\hline Work and school & \multicolumn{3}{|c|}{-} & $\begin{array}{l}\text { Relating to participating } \\
\text { in work/school activities }\end{array}$ \\
\hline Family planning & \multicolumn{3}{|c|}{-} & $\begin{array}{l}\text { Relating to starting and } \\
\text { caring for a family }\end{array}$ \\
\hline Total & 8 domains & 10 domains & 12 domains & 10 domains \\
\hline
\end{tabular}

Table S2 Pathfinder ${ }^{\mathrm{TM}} 2$ and Pathfinder ${ }^{\mathrm{TM}} 5$ ethics committee approval list

\begin{tabular}{|c|c|}
\hline \multicolumn{2}{|c|}{ Pathfinder ${ }^{\mathrm{TM}} 2$ ethics committee approval list } \\
\hline Country & Institutional review boards name \\
\hline \multirow[t]{5}{*}{ Australia } & RCH Human Research Ethics \\
\hline & Committee \\
\hline & Royal Children's Hospital Melbourne \\
\hline & Flemington Road, Parkville \\
\hline & VIC 3052 \\
\hline \multirow[t]{6}{*}{ Australia } & Sydney Local Health District Ethics \\
\hline & Review Committee (RPAH Zone) \\
\hline & Research Development Office \\
\hline & Royal Prince Alfred Hospital \\
\hline & Missenden Road, Camperdown \\
\hline & NSW 2050 \\
\hline \multirow[t]{3}{*}{ Brazil } & Comitê de Ética em Pesquisa - CEP \\
\hline & HEMORIO \\
\hline & R. Frei Caneca, 8 - CEP 202II-030 - Rio de Janeiro/RJ \\
\hline \multirow[t]{5}{*}{ Brazil } & Comitê de Ética em Pesquisa do Hospital \\
\hline & De Transplante Euryclides de Jesus \\
\hline & Zerbini \\
\hline & Av. Brigadeiro Luis Antonio, $2651-2^{\circ}$ \\
\hline & Andar - CEP 0I40I-90I - São Paulo - SP \\
\hline
\end{tabular}

(Continued)
Table S2 (Continued)

\begin{tabular}{|l|l|}
\hline Country & Institutional review boards name \\
\hline \multirow{5}{*}{ Brazil } & Comitê de Ética em Pesquisa em Seres \\
\cline { 2 - 3 } & Humanos da Faculdade de Ciências \\
\cline { 2 - 3 } & Médicas - UNICAMP/SP \\
\cline { 2 - 3 } & Rua Tessália Vieira de Camargo, I26 - \\
\cline { 2 - 3 } & Cidade Universitária Zeferino Vaz - \\
\cline { 2 - 3 } & Barão Geraldo \\
\cline { 2 - 3 } & CEP I3083-887 - Campinas - SP \\
\hline \multirow{5}{*}{ Brazil } & Comitê de Ética em Pesquisa em Seres \\
\cline { 2 - 3 } & Humanos do Hospital de Crianças César \\
\cline { 2 - 3 } & Pernetta e Hospital Pequeno Príncipe - \\
\cline { 2 - 3 } & PR \\
\cline { 2 - 3 } & Rua Desembargador Motta, I070 - CEP \\
\cline { 2 - 3 } & $80250-060-$ Curitiba - PR \\
\hline & Ethics Committee for Multicentre \\
\cline { 2 - 3 } & Clinical Trials \\
\cline { 2 - 3 } & 5 Sveta Nedelya square \\
\cline { 2 - 3 } & Sofia I000 \\
\hline Croatia & Central Ethics Committee \\
\cline { 2 - 3 } & Ksaverska cesta 4 \\
\cline { 2 - 3 } & I0 000 Zagreb, Croatia \\
\hline
\end{tabular}

(Continued) 
Table S2 (Continued)

\begin{tabular}{|c|c|}
\hline Country & Institutional review boards name \\
\hline \multirow[t]{4}{*}{ Denmark } & De Videnskabsetiske Komiteer for \\
\hline & Region Midtjylland \\
\hline & Skottenborg 26 \\
\hline & 8800 Viborg \\
\hline \multirow[t]{5}{*}{ Denmark } & Region Hovedstaden \\
\hline & De Videnskabsetiske Komiteer for \\
\hline & Region Hovedstaden \\
\hline & Kongens Vænge 2 \\
\hline & 3400 Hillerød \\
\hline \multirow[t]{5}{*}{ France } & Comité de Protection des Personnes lle \\
\hline & De France II \\
\hline & Centre Universitaire des Saints-Pères \\
\hline & 45 rue des Saints-Pères \\
\hline & 75006 Paris \\
\hline \multirow[t]{5}{*}{ Germany } & Ethik-Kommission des Fachbereichs \\
\hline & Medizin der Johann-Wolfgang-Goethe \\
\hline & Universität \\
\hline & Theodor-Stern-Kai 7 \\
\hline & 60590 Frankfurt/M. \\
\hline \multirow[t]{2}{*}{ Hungary } & $\begin{array}{l}\text { Medical Research Council Committee for Clinical } \\
\text { Pharmacology }\end{array}$ \\
\hline & H-I05I Budapest, Arany J. u. 6-8. \\
\hline \multirow[t]{3}{*}{ Israel } & Chairman of Helsinki Committee \\
\hline & Sheba Medical Center \\
\hline & Tel Hashomer \\
\hline \multirow[t]{5}{*}{ Italy } & Comitato Etico aziendale dell 'Azienda \\
\hline & Ospedaliero-Universitaria S. Maria della \\
\hline & Misericordia di Udine \\
\hline & Via Colugna 50 \\
\hline & 33100 Udin \\
\hline \multirow[t]{4}{*}{ Italy } & Comitato Etico Locale Azienda \\
\hline & Ospedaliero-Universitaria Careggi \\
\hline & Pad. 3 Nuovo Ingresso Careggi - \\
\hline & Didattica II piano stanze 2 |I-2/2 \\
\hline \multirow[t]{4}{*}{ Italy } & Comitato Etico per la sperimentazione \\
\hline & Clinica della provincia di Vicenza \\
\hline & Via Rodolfi 37 \\
\hline & 36100 Vicenza \\
\hline \multirow[t]{5}{*}{ Italy } & Comitato Etico \\
\hline & Ospedale Maggiore Policlinico, \\
\hline & Mangiagalli e Regina Elena di Milano \\
\hline & Via Francesco Sforza 28 \\
\hline & 20122 Milano \\
\hline \multirow[t]{3}{*}{ Japan } & IRB of Gosyozuka Clinic \\
\hline & I-2I-4, Gosyozuka, Miyamae-ku, \\
\hline & Kawasaki-shi, Kanagawa, 2I6-002I \\
\hline
\end{tabular}

(Continued)
Table S2 (Continued)

\begin{tabular}{|c|c|}
\hline Country & Institutional review boards name \\
\hline \multirow[t]{3}{*}{ Japan } & IRB of Hiroshima University Hospital \\
\hline & I-2-3 Kasumi, Minami-Ku, \\
\hline & Hiroshima-shi, Hiroshima, 734-855I \\
\hline \multirow[t]{3}{*}{ Japan } & IRB of Jichi Medical University Hospital \\
\hline & 33II-I Yakushiji, Shimotsukeshi, \\
\hline & Tochigi, 329-0498 \\
\hline \multirow[t]{3}{*}{ Japan } & IRB of Nagoya University Hospital \\
\hline & 65 Tsurumai-cho, Showaku, \\
\hline & Nagoya-shi, Aichi, 466-8560 \\
\hline \multirow[t]{3}{*}{ Japan } & IRB of Nara Medical University Hospital \\
\hline & 840 Shijo-cho, Kashiharashi, \\
\hline & Nara, 634-8522 \\
\hline \multirow[t]{3}{*}{ Japan } & IRB of Ogikubo Hospital \\
\hline & 3-I-24, Imagawa, Suginami-ku, \\
\hline & Tokyo, 167-0035 \\
\hline \multirow[t]{4}{*}{ Japan } & IRB of Research Hospital of the Institute of \\
\hline & Medical Science, The University of Tokyo \\
\hline & 4-6-I, Shirokanedai, Minato-ku, \\
\hline & Tokyo, 108-8639 \\
\hline \multirow[t]{3}{*}{ Japan } & IRB of Shizuoka Children's Hospital \\
\hline & 860 Urushiyama, Aoi-ku, \\
\hline & Shizuoka-shi, Shizuoka, 420-8660 \\
\hline \multirow[t]{4}{*}{ Japan } & IRB of St Marianna University School of \\
\hline & Medicine Hospital \\
\hline & 2-16-I Sugao Miyamae-ku, \\
\hline & Kawasaki-shi, Kanagawa, 216-85।I \\
\hline \multirow[t]{4}{*}{ Japan } & IRB of Tokyo Medical University \\
\hline & Hospital \\
\hline & 6-7-I Nishishinjuku, Shinjukuku, \\
\hline & Tokyo, 160-0023 \\
\hline \multirow[t]{4}{*}{ Japan } & IRB of University Hospital of Occupational \\
\hline & And Environmental Health \\
\hline & I-I, Iseigaoka, Yahata-nishi-ku, \\
\hline & Kitakyushu-shi, Fukuoka, 807-8555 \\
\hline \multirow[t]{6}{*}{ Korea } & Eulji University Hospital's \\
\hline & Institutional Review Board \\
\hline & Daejeon Eulji University Hospital \\
\hline & I306, Dun-san 2-Dong, \\
\hline & Seo-Gu, Daejeon 302-799, \\
\hline & Republic of Korea \\
\hline \multirow[t]{5}{*}{ Malaysia } & Medical Research \& Ethics Committee \\
\hline & National Institute of Health \\
\hline & D/A Institut Pengurusan Kesihatan \\
\hline & Jalan Rumah Sakit, Bangsar, \\
\hline & 59000 Kuala Lumpur \\
\hline
\end{tabular}

(Continued) 
Table S2 (Continued)

\begin{tabular}{|c|c|}
\hline Country & Institutional review boards name \\
\hline \multirow[t]{5}{*}{ Norway } & Regional komité for medisinsk og \\
\hline & Helsefaglig forskningsetikk, \\
\hline & REK sør-øst C \\
\hline & Gullhaugveien I-3, \\
\hline & NO-0484 Oslo \\
\hline \multirow[t]{3}{*}{ Russia } & $\begin{array}{l}\text { Ethics Committee at Ministry of Health of the Russian } \\
\text { Federation }\end{array}$ \\
\hline & 3, Rakhmanovsky lane, I2705 I \\
\hline & Moscow \\
\hline \multirow[t]{4}{*}{ Spain } & Committee Hospital Universitario La \\
\hline & $\mathrm{Paz}$ \\
\hline & Paseo de la Castellana, 26I \\
\hline & 28046 Madrid \\
\hline \multirow[t]{9}{*}{ Spain } & Ethics and Biomedic Committee of \\
\hline & Andalucia \\
\hline & CCEIBA \\
\hline & Consejería de Salud \\
\hline & Secretaría General de Calidad y \\
\hline & Modernización \\
\hline & Comité Autonómico de Ensayos Clínicos \\
\hline & Avd. Innovación s/n. Edificio Arena I \\
\hline & 41020 - Sevilla \\
\hline \multirow[t]{3}{*}{ Sweden } & Regionala etikprövningsnämnden i Lund \\
\hline & Box 133 \\
\hline & 22 I 00 Lund \\
\hline \multirow[t]{4}{*}{ Switzerland } & Commission cantonale (VD) d'éthique de \\
\hline & la recherche sur l'être humain \\
\hline & Avenue. de Chailly 23 \\
\hline & I012 Lausanne \\
\hline \multirow[t]{4}{*}{ Switzerland } & Commission cantonale d'éthique de \\
\hline & la recherche sur l'être humain HUG \\
\hline & Rue Gabriel-Perret-Gentil 4 \\
\hline & I2II Genève I4 \\
\hline \multirow[t]{3}{*}{ Switzerland } & Kantonale Ethikkommission (KEK) \\
\hline & Stampfenbachstrasse 121 \\
\hline & 8090 Zürich \\
\hline \multirow[t]{5}{*}{ Taiwan } & Changhua Christian Hospital \\
\hline & Institutional Review Board \\
\hline & Center for Clinical Trials, Child \\
\hline & Building, No I35, Nanhsiao Street, \\
\hline & Changhua 500, Taiwan (R.O.C) \\
\hline \multirow[t]{4}{*}{ Taiwan } & National Taiwan University Hospital \\
\hline & Research Ethics Committee \\
\hline & No I Changde St., Zhongzheng Dist, \\
\hline & Taipei City I00, Taiwan (R.O.C) \\
\hline
\end{tabular}

(Continued)
Table S2 (Continued)

\begin{tabular}{|c|c|}
\hline Country & Institutional review boards name \\
\hline \multirow{4}{*}{$\begin{array}{l}\text { the } \\
\text { Netherlands }\end{array}$} & Erasmus MC \\
\hline & Medische Ethische Toetsings Commissie \\
\hline & Dr Molewaterplein 50 \\
\hline & 3015 GE Rotterdam \\
\hline \multirow[t]{5}{*}{ Turkey } & Ege University Medical Faculty Clinical \\
\hline & Research Ethics Committee \\
\hline & Ege University Medical Faculty \\
\hline & Dean's Office 2nd Floor \\
\hline & Bornova IZMiR 35I00 \\
\hline \multirow[t]{7}{*}{ UK } & Basingstoke and North Hampshire \\
\hline & Hospitals NHS Foundation Trust \\
\hline & Research \& Development \\
\hline & $\mathrm{Rm} 32$, F Floor \\
\hline & Aldermaston Road \\
\hline & Basingstoke \\
\hline & RG24 9NA \\
\hline \multirow[t]{7}{*}{ UK } & Cardiff and Vale University Local Health \\
\hline & Board \\
\hline & Second Floor, Tower Block Two, Room 3 \\
\hline & University Hospital of Wales \\
\hline & Heath Park \\
\hline & Cardiff \\
\hline & CFI 4 4XN \\
\hline \multirow[t]{8}{*}{ UK } & London - Hampstead \\
\hline & Health Research Authority \\
\hline & National Research Ethics Service (NRES) \\
\hline & Ground Floor \\
\hline & Skipton House \\
\hline & 80 London Road \\
\hline & London \\
\hline & SEI $6 \mathrm{LH}$ \\
\hline \multirow[t]{7}{*}{ UK } & Oxford University Hospitals NHS Trust \\
\hline & Research and Development Department \\
\hline & Joint Research Office, Block 60 \\
\hline & Churchill Hospital \\
\hline & Old Road \\
\hline & Headington \\
\hline & Oxford, OX3 7LJ \\
\hline \multirow[t]{6}{*}{ UK } & Royal Free Hampstead NHS Trust \\
\hline & Research \& Development \\
\hline & Royal Free Hospital \\
\hline & Pond Street \\
\hline & London \\
\hline & NW3 2QG \\
\hline
\end{tabular}

(Continued) 
Table S2 (Continued)

\begin{tabular}{|c|c|}
\hline Country & Institutional review boards name \\
\hline \multirow[t]{5}{*}{ UK } & Sheffield Teaching Hospitals NHS \\
\hline & Foundation Trust \\
\hline & 305 Western Bank \\
\hline & Sheffield \\
\hline & SIO 2TJ \\
\hline \multirow[t]{5}{*}{ UK } & The Joint Clinical Trials Office \\
\hline & 16th Floor Tower Wing \\
\hline & Guy's Hospital \\
\hline & Great Maze Pond \\
\hline & SEI 9RT \\
\hline \multirow[t]{4}{*}{ US } & Arizona Hemo \& Throm Center at \\
\hline & Phoenix Children's Hospital I919 E \\
\hline & Thomas Rd \\
\hline & Phoenix, AZ 850I6-77I0 \\
\hline \multirow[t]{3}{*}{ US } & Children's Hospital 200 Henry Clay Ave \\
\hline & Ste 3203 \\
\hline & New Orleans, LA 70II8-5720 \\
\hline \multirow[t]{3}{*}{ US } & Children's Hospital Boston \\
\hline & 300 Longwood Ave \\
\hline & Boston, MA 02115 \\
\hline \multirow[t]{4}{*}{ US } & Children's Hospitals and Clinics of \\
\hline & Minnesota 2530 Chicago Avenue South \\
\hline & Mail Stop CSC 220 \\
\hline & Minneapolis, MN 55404 \\
\hline \multirow[t]{4}{*}{ US } & Children's Hospital Michigan 87 East \\
\hline & Canfield \\
\hline & Second Floor \\
\hline & Detroit, MI 4820I \\
\hline \multirow[t]{5}{*}{ US } & Childrens Hospital of Philadelphia Research \\
\hline & Institute \\
\hline & 3535 Market St \\
\hline & Suite 1200 \\
\hline & Philadelphia, PA 19104 \\
\hline \multirow[t]{5}{*}{ US } & Children's Hospital of the Kings Daughters \\
\hline & 72I Fairfax Avenue \\
\hline & Andrews Hall \\
\hline & Suite 128 \\
\hline & Norfolk, VA 23507 \\
\hline \multirow[t]{3}{*}{ US } & Children's Medical Center One Children's \\
\hline & Plaza \\
\hline & Dayton, $\mathrm{OH} 45404$ \\
\hline \multirow[t]{3}{*}{ US } & Children's National Medical Center 35357 \\
\hline & 7th Avenue SW \\
\hline & Olympia, WA 98502-5010 \\
\hline
\end{tabular}

(Continued)
Table S2 (Continued)

\begin{tabular}{|c|c|}
\hline Country & Institutional review boards name \\
\hline \multirow[t]{4}{*}{ US } & Cincinnati Children's Hospital Medical \\
\hline & Center 3333 Burnett Ave \\
\hline & MLC 5020 \\
\hline & Cincinnati, OH 45229 \\
\hline \multirow[t]{4}{*}{ US } & Georgetown University Hospital 3900 \\
\hline & Reservoir Road NW \\
\hline & SWI04 Medical Dental Building \\
\hline & Washington, DC 20057 \\
\hline \multirow[t]{4}{*}{ US } & GHSU Adult Hemophilia Center 7063 \\
\hline & Columbia Gateway Drive \\
\hline & Suite 110 \\
\hline & Columbia, MD 21046 \\
\hline \multirow[t]{3}{*}{ US } & Harbor-UCLA Medical Center II 24 \\
\hline & West Carson Street \\
\hline & Torrance, CA 90502-2004 \\
\hline \multirow[t]{3}{*}{ US } & Hemophilia Treatment Center 35357 7th \\
\hline & Ave SW \\
\hline & Olympia, WA 98502 \\
\hline \multirow[t]{4}{*}{ US } & Johns Hopkins University \\
\hline & 1620 McElderry Street \\
\hline & Reed Hall, Suite B-I 30 \\
\hline & Baltimore, MD 2/205 \\
\hline \multirow[t]{5}{*}{ US } & Medical University of SC Harborview \\
\hline & Office Tower \\
\hline & I9 Hagood Avenue \\
\hline & Suite 60I MSC 857 \\
\hline & Charleston, SC 29425 \\
\hline \multirow[t]{2}{*}{ US } & Michigan State University 207 Olds Hall \\
\hline & East Lansing, MI 48824 \\
\hline \multirow[t]{3}{*}{ US } & Miller Children's Hospital Long Beach \\
\hline & 280I Atlantic Ave \\
\hline & Long Beach, CA 90806 \\
\hline \multirow[t]{4}{*}{ US } & Nemours Children's Clinic Orlando \\
\hline & Hematology/Oncology 807 Children's \\
\hline & Way \\
\hline & Jacksonville, FL 32207 \\
\hline \multirow[t]{2}{*}{ US } & OHSU 3।8I SW Sam Jackson Park Road \\
\hline & Portland, OR 97239 \\
\hline \multirow[t]{6}{*}{ US } & Pediatric Hemophilia Program University \\
\hline & UPR Medical Science Campus - IRB \\
\hline & Main Building \\
\hline & 2nd Floor office A-236 \\
\hline & PO Box 365067 \\
\hline & San Juan, PR 00936-5067 \\
\hline
\end{tabular}

(Continued) 
Table S2 (Continued)

\begin{tabular}{|c|c|}
\hline Country & Institutional review boards name \\
\hline \multirow[t]{6}{*}{ US } & Providence Sacred Heart Medical Center \\
\hline & \& Children's Hospital Fifth \& Browne \\
\hline & Medical Center \\
\hline & I04 West Fifth Ave \\
\hline & Suite 200W \\
\hline & Spokane, WA 99204 \\
\hline \multirow[t]{5}{*}{ US } & St Christophers Hospital for Child I60I \\
\hline & Cherry St \\
\hline & 3 Parkway Building \\
\hline & Suite 10444 \\
\hline & Philadelphia, PA 19102 \\
\hline \multirow[t]{3}{*}{ US } & St Lukes Mtn States Tmr Institue \\
\hline & I 90 East Bannock St. \\
\hline & Boise, ID 837I2 \\
\hline \multirow[t]{4}{*}{ US } & St Michael's Medical Center St \\
\hline & Michael's Medical Center IRB \\
\hline & III Central Avenue \\
\hline & Newark, NJ 07I02 \\
\hline \multirow[t]{3}{*}{ US } & Tampa Children's Hospital \\
\hline & 300 I West Dr. Martin Luther King Jr. Blvd \\
\hline & Tampa, FL 33607 \\
\hline \multirow[t]{3}{*}{ US } & Texas Children's Hospital \\
\hline & One Baylor Plaza \#600D \\
\hline & Houston, TX 77030 \\
\hline \multirow[t]{5}{*}{ US } & $\begin{array}{l}\text { The Gulf States Hemophilia \& Thrombophilia Center } \\
\text { Cheaspeake }\end{array}$ \\
\hline & Research Review, Inc. \\
\hline & 7063 Columbia Gateway Dr \\
\hline & Suite 110 \\
\hline & Columbia, MD 211046 \\
\hline \multirow[t]{4}{*}{ US } & U.C. Davis Hemophilia Research Center \\
\hline & 292 I Stockton Blvd. \\
\hline & CTSC Bldg. Suite I400 Rm I429 \\
\hline & Sacramento, CA 95817 \\
\hline \multirow[t]{5}{*}{ US } & University of Nebraska Medical Center \\
\hline & Academic and Research Services \\
\hline & Building 3000 \\
\hline & 987830 Nebraska Medical Center \\
\hline & Omaha, NE 58I98 \\
\hline \multirow[t]{5}{*}{ US } & University of Virginia Hospital UVA \\
\hline & Institutional Review Board for Health \\
\hline & Science Research \\
\hline & P.O. Box 80043 \\
\hline & Charlottesville, VA 22908 \\
\hline \multirow[t]{3}{*}{ US } & Vanderbilt Hemost-Throm Clinic 504 \\
\hline & Oxford House \\
\hline & Nashville, TN 37232-6869 \\
\hline \multirow[t]{3}{*}{ US } & WIRB \\
\hline & 3535 7th Ave SW \\
\hline & Olympia, WA 98502 \\
\hline
\end{tabular}

Table S2 (Continued)

\begin{tabular}{|c|c|}
\hline \multicolumn{2}{|c|}{ Pathfinder ${ }^{\mathrm{TM}} 5$ ethics committee approval list } \\
\hline Country & Institutional review boards name \\
\hline \multirow[t]{3}{*}{ Canada } & The Hospital for Sick Children \\
\hline & 555 University Avenue \\
\hline & Toronto, ON M5G IX8 \\
\hline \multirow[t]{5}{*}{ France } & CPP SUD-OUEST et OUTRE-MER IV \\
\hline & Centre Hospitalier ESQUIIROL \\
\hline & Cabanis Haut \\
\hline & I5 rue du Docteur Marcland \\
\hline & 87025 LIMOGES CEDEX \\
\hline \multirow[t]{4}{*}{ Germany } & Ethik-Kommission der \\
\hline & Ärztekammer Nordrhein \\
\hline & Tersteegenstraße 9 \\
\hline & 40474 Düsseldorf \\
\hline \multirow[t]{4}{*}{ Greece } & General Hospital of Thessaloniki \\
\hline & “Ippokrateio" \\
\hline & 49, Konstantinoupoleos str, Athens, GR- \\
\hline & 54642 \\
\hline \multirow[t]{5}{*}{ Greece } & General Paediatric Hospital of Athens \\
\hline & "Agia Sofia" \\
\hline & Thivon \& Papadiamantopoulou str, \\
\hline & Goudi, Athens, \\
\hline & GR-II 527 \\
\hline \multirow[t]{3}{*}{ Israel } & Chairman of Helsinki Committee \\
\hline & Sheba Medical Center \\
\hline & Tel Hashomer \\
\hline \multirow[t]{4}{*}{ Italy } & Comitato Etico per la sperimentazione \\
\hline & clinica della provincia di Vicenza \\
\hline & Via Rodolfi 37 \\
\hline & 36100 Vicenza \\
\hline \multirow[t]{3}{*}{ Japan } & IRB of Ogikubo Hospital, \\
\hline & Address: 3-I-24, Imagawa, Suginami-ku, \\
\hline & Tokyo, 167-0035 Japan \\
\hline \multirow[t]{5}{*}{ Japan } & IRB of University Hospital of \\
\hline & Occupational and Environmental Health, \\
\hline & Address: I-I, Iseigaoka, Yahata-nishi-ku, \\
\hline & Kitakyushu, Fukuoka, 807-8555, \\
\hline & Japan \\
\hline \multirow[t]{4}{*}{ Lithuania } & Lithuanian Bioethics Committee \\
\hline & Didzioji str 22 \\
\hline & LT-0II 28 \\
\hline & Vilnius \\
\hline \multirow[t]{5}{*}{ Malaysia } & Medical Research \& Ethics Committee \\
\hline & National Institute of Health \\
\hline & D/A Institut Pengurusan Kesihatan \\
\hline & Jalan Rumah Sakit, Bangsar \\
\hline & 59000 Kuala Lumpur \\
\hline
\end{tabular}

(Continued) 
Table S2 (Continued)

\begin{tabular}{|c|c|}
\hline Country & Institutional review boards name \\
\hline \multirow[t]{4}{*}{ Portugal } & Comissão de Ética para a Investigação Clínica \\
\hline & Parque da Saúde de Lisboa \\
\hline & Av. do Brasil, 53 Pav. I7A \\
\hline & 1749-004 Lisboa \\
\hline \multirow[t]{4}{*}{ Switzerland } & Comitato Etico Cantonale \\
\hline & c/o Ufficio di Sanità \\
\hline & Via Orico 5 \\
\hline & $\mathrm{CH}-650 \mathrm{I}$ Bellinzona \\
\hline \multirow[t]{5}{*}{ Switzerland } & Ethikkommission des Kantons Luzern \\
\hline & Dienststelle Gesundheit \\
\hline & Meyerstrasse 20 \\
\hline & Postfach 3439 \\
\hline & $\mathrm{CH}-6002$ Luzern \\
\hline \multirow[t]{4}{*}{ Switzerland } & Ethikkommission Nordwest- und \\
\hline & Zentralschweiz (EKNZ) \\
\hline & Hebelstrasse 53 \\
\hline & $\mathrm{CH}-4056$ Basel \\
\hline \multirow[t]{4}{*}{ Switzerland } & Kantonale Ethikkommission Zürich \\
\hline & Abteilung B \\
\hline & Stampfenbachstrasse 121 \\
\hline & $\mathrm{CH}-8090$ Zürich \\
\hline \multirow[t]{3}{*}{ Turkey } & Kocaeli Universitesi Klinik Arastirmalar Etik Kurulu \\
\hline & Kocaeli Universitesi Klinik Arastirmalar Birimi \\
\hline & Umuttepe Yerleșkesi - Kocaeli \\
\hline \multirow[t]{2}{*}{ Ukraine } & $\begin{array}{l}\text { The Ethic Committee of SI "Institute of Urgent and } \\
\text { Recovery Surgery n.a. V.K Gusak, NAMS of Ukraine." }\end{array}$ \\
\hline & 45, gen. Chuprynky str., Lviv 49004, Ukarine \\
\hline \multirow[t]{2}{*}{ Ukraine } & $\begin{array}{l}\text { The Ethic Committee SI "Institute of blood pathology } \\
\text { and transfusion medicine of NAMS" }\end{array}$ \\
\hline & 45, gen. Chuprynky str., Lviv 49004 \\
\hline \multirow[t]{7}{*}{ UK } & Central Ethics \\
\hline & North East - Newcastle and North \\
\hline & Tyneside I REC, \\
\hline & Room 002, TEDCO Business Centre, \\
\hline & Rolling Mill Road, \\
\hline & Jarrow, \\
\hline & NE32 3DT \\
\hline \multirow[t]{5}{*}{ UK } & Clinical Research Network South London \\
\hline & 16th Floor BRC Facility \\
\hline & Guy’s Tower, Guy's Hospital \\
\hline & Great Maze Pond \\
\hline & London SEI 9RT \\
\hline \multirow[t]{5}{*}{ UK } & King's Health Partners \\
\hline & Clinical Trials Office \\
\hline & Floor 16, Tower Wing \\
\hline & Great Maze Pond \\
\hline & London SEI 9RT \\
\hline
\end{tabular}

(Continued)
Table S2 (Continued)

\begin{tabular}{|c|c|}
\hline Country & Institutional review boards name \\
\hline \multirow[t]{7}{*}{ UK } & Oxford University Hospitals NHS Trust \\
\hline & From the R\&D Level \\
\hline & OUH Research \& Development \\
\hline & Joint Research Office, Block 60 \\
\hline & Churchill Hospital \\
\hline & Old Road, Headington \\
\hline & Oxford OX3 7LJ \\
\hline \multirow[t]{7}{*}{ UK } & University Hospitals of Leicester NHS \\
\hline & Trust \\
\hline & Research \& Development Office \\
\hline & Leicester General Hospital \\
\hline & Gwendolen Road \\
\hline & Leicester \\
\hline & LE5 4PW \\
\hline \multirow[t]{4}{*}{ US } & Arizona Hemo \& Throm Center at \\
\hline & Phoenix Childrens Hospital \\
\hline & 1919 E Thomas Rd \\
\hline & Phoenix, AZ 850I6-77I0 \\
\hline \multirow[t]{4}{*}{ US } & Children's Hospital of Philadelphia \\
\hline & I I th Floor, CTRB I I 200-28 \\
\hline & 350I Civic Center Blvd. \\
\hline & Philadelphia, PA 19104 \\
\hline \multirow[t]{4}{*}{ US } & Children's Hospitals and Clinics of Minnesota \\
\hline & 2525 Chicago Avenue S. \\
\hline & CSC-I75 \\
\hline & Minneapolis, MN 55404 \\
\hline \multirow[t]{5}{*}{ US } & Louisiana State University Health \\
\hline & Sciences Center \\
\hline & 433 Bolivar street \\
\hline & Suite 206D \\
\hline & New Orleans, LA 70II2 \\
\hline \multirow[t]{4}{*}{ US } & Medical University of South Carolina \\
\hline & Hematology/Pathology \\
\hline & I65 Ashley Ave \\
\hline & Charleston, SC 29425 \\
\hline \multirow[t]{5}{*}{ US } & North Shore Long Island Jewish Medical \\
\hline & Center \\
\hline & 270-05 76th Ave \\
\hline & Suite 358 \\
\hline & New Hyde Park, NY I I 040 \\
\hline \multirow[t]{5}{*}{ US } & Pediatric Hemophilia Program \\
\hline & University \\
\hline & Pediatric Hospital 2nd Floor Office \\
\hline & 2-25 Rio Piedras Medical Center \\
\hline & San Juan, PR 00935 \\
\hline
\end{tabular}

(Continued) 
Table S2 (Continued)

\begin{tabular}{|l|l|}
\hline Country & Institutional review boards name \\
\hline \multirow{4}{*}{ US } & Texas Children's Hospital \\
\cline { 2 - 3 } & 662 I Fannin Street \\
\cline { 2 - 3 } & Houston, TX 77030 \\
\hline \multirow{4}{*}{ US } & University of Virginia Medical Center \\
\cline { 2 - 3 } & I22I Lee St \\
\cline { 2 - 2 } & 4th Floor, Primary Care Center \\
\cline { 2 - 2 } & Charlottesville, VA 22908 \\
\hline \multirow{4}{*}{ US } & Vanderbilt Hemost-Throm Clinic \\
\cline { 2 - 2 } & 2200 Children's Way, 6I05 DOT \\
\cline { 2 - 2 } & Nashville, TN 37232-9830 \\
\hline & Western Institutional Review Board \\
\cline { 2 - 2 } & 3535 7th Avenue SW \\
\cline { 2 - 2 } & Olympia, WA 98502-5010 \\
\hline
\end{tabular}

\section{Publish your work in this journal}

Patient Preference and Adherence is an international, peer-reviewed, open access journal that focuses on the growing importance of patient preference and adherence throughout the therapeutic continuum. Patient satisfaction, acceptability, quality of life, compliance, persistence and their role in developing new therapeutic modalities and compounds to optimize clinical outcomes for existing disease states are major areas of interest for the journal. This journal has been accepted for indexing on PubMed Central. The manuscript management system is completely online and includes a very quick and fair peer-review system, which is all easy to use. Visit http://www. dovepress.com/testimonials.php to read real quotes from published authors.

\footnotetext{
Submit your manuscript here: http://www.dovepress.com/patient-preference-and-adherence-journal
} 